Sharif University of Technology
Scientia Iranica
SCIENTIA
I RAN I CA

\title{
Vertical vibration control of suspension bridges subjected to earthquake by semi-active MR dampers
}

\author{
S. Pourzeynali*, A. Bahar and S. Pourzeynali \\ Department of Civil Engineering, Faculty of Engineering, University of Guilan, Rasht, Iran.
}

Received 17 November 2014; received in revised form 4 September 2015; accepted 13 February 2016

\section{KEYWORDS}

Rigid truss;

Semi-active control;

Suspension bridge;

MR damper;

Vertical vibration;

Earthquake

excitation.

\begin{abstract}
In this paper, a semi-active control technique is presented to mitigate the seismic vertical response of suspension bridges using Magneto-Rheological (MR) dampers. MR dampers, as semi-active control devices, have received significant attention in recent years because of their adaptability of working as active control devices without requiring large power of sources. The most challenging problem in this study is how to install the dampers at the degrees along the bridge span far from the towers. In the present paper, to solve this problem, a "rigid truss", which is attached to the bottom of the bridge deck, is proposed. The MR damper can be installed between the bridge deck and free-end of the truss. For numerical study, the Vincent-Thomas suspension bridge is chosen and different schemes, in point of number and location of the dampers view, are proposed to get optimal performance of the dampers in reducing the bridge vertical responses. To reach this goal, all of the schemes are optimized, and the controlled and uncontrolled responses of the bridge are calculated under application of 15 major world-wide earthquake accelerogrames. The results indicate that the proposed models can effectively reduce the vertical responses of the example bridge.
\end{abstract}

(C) 2017 Sharif University of Technology. All rights reserved.

\section{Introduction}

Cable-supported bridges have received great attention in recent years because of their advantages such as elegant appearance as well as convenience in bridging long spans. These structures are highly vulnerable to dynamic loads, such as earthquakes and strong winds, due to their high flexibility and low structural damping. Therefore, the vibration control of these bridges is an important issue to keep them safe and serviceable. In the present study, suspension bridges are focused on controlling their vertical responses against earthquake excitations.

\footnotetext{
*. Corresponding author. Fax: +981333690271 Email addresses: pourzeynali@guilan.ac.ir (Saeid Pourzeynali); bahar@guilan.ac.ir (A.bahar); solmazpourzeynali@gmail.com (Solmaz Pourzeynali)
}

There are generally two main strategies to reduce seismic responses of suspension bridges including strengthening by use of traditional methods to increase the capacity of bridge to resist the seismic demand and using the control devices among which the energy dissipative devices, such as MR dampers, are known as the most important ones to minimize the damage caused by the ground motion of strong earthquakes. Both approaches can also be used to aim for an optimal solution [1].

In recent decades, many control systems, such as active dampers [2,3], tuned mass damper [4,5], viscous dampers [6], and tuned liquid column dampers [7], have been studied for seismic control of long span bridges and tall buildings, but there have always been some challenges such as cost and maintenance, reliance on external power, etc. To overcome these challenges, semi-active control devices have been proposed. These 
systems combine the best features of passive and active control devices, and they do not need a large power source which is so critical during seismic events when power failing may occur [8-10].

Various types of semi-active control devices with different control algorithms have been studied to control the response of bridges, which most of them have been performed to control the longitudinal responses. To direct comparison among these control studies, the benchmark Bill Emerson Memorial Bridge crossing the Mississippi River was developed [11]. Performance of different semi-active control devices, such as Resetting Semi-Active Stiffness Dampers, switching Semi-Active Stiffness Dampers, Magneto-rheological dampers, and Semi-Active Friction Dampers, have been investigated for this bridge [12].

Agrawal et al. [13] proposed Semi-Active Stiffness Damper (SASD) which can operate in the resetting mode (RSASD) or switching mode (SSASD). They analyzed performances of both and concluded that although SSASD reduces the responses compared to uncontrolled ones, the reduction ratio is less than that of the RSASD. In addition, they concluded that the RSASD reduction level was comparable to that of the sample active controller. They also investigated the performance of Semi-Active Friction Damper (SAFD). They noted that the friction damper should be combined with linear elastic spring to be able to add the stiffness after that sliding starts in the damper.

Jung et al. [14] verified the performance of smart dampers. The results demonstrated that smart damping systems have generally the same performance as the active control system.

Moon et al. [15] investigated the performance of sliding mode control in lieu of LQG formulation using MR dampers. Comparison of the results indicated that MR dampers are more effective than the active control systems.

Magneto-rheological dampers have received significant attention as a seismic retrofit control system due to their great advantages such as low power consumption, force controllability, large force capacity, rapid response, and safe manner operation in case of power fail $[9,16,17]$. MR dampers have been mainly applied to vibration control of highway bridges, cable supported bridges, and tall buildings [18-22]. Many mathematical models have been proposed to model the intrinsic non-linear behavior of MR dampers such as Bingham model, viscoelastic-plastic model, BoucWen model, phenomenological model, improved BoucWen model, modified Dahl model, normalized Boucwen model, and many others. Some of these models, such as the Bingham model, cannot capture well the force-velocity non-linear behavior of the damper. It is very important for a model to be able to portray the non-linear behavior of the damper and easily identify the system parameters [9,23-26]. Jung et al. [18] examined the application of MR dampers with a comprehensive study of the adequacy of different types of dynamic models for MR fluid dampers, such as Bingham model, Bouc-Wen model, and modified BoucWen model. The results indicated that the application of MR control system is generally similar to that of the active control system; the Bouc-Wen model and the modified Bouc-Wen model were also shown to be more computationally tractable than the others.

Bing et al. [27] investigated the application of MR dampers in reducing structural responses of cablestayed bridges under multi-support excitations. The numerical results of that study showed that the performance of the MR damper is nearly the same as that of the active control system, and in some cases, it is better than the active system while requiring significantly less power than the active one.

Alapati et al. [12] conducted a comparison between different semi-active strategies investigated for the benchmark bridge. They concluded that among semi-active control systems studied, the modified BoucWen model of MR dampers gave overall robust performance in point of response reduction view.

Also, there was a study by Yang et al. [21] on Pingsheng Bridge. A phenomenological model of MR damper was used in this study. The effect of variable current and number of dampers on seismic response control was investigated. The results showed that the longitudinal displacement of the tower top and bridge girder decrease with the increase in input current and number of MR dampers attached.

There are six long bridges in the Golden State that the California Department of Transportation (Caltrans) decided to upgrade them seismically after two major earthquakes (Loma Prieta earthquake of October 1989, and Northridge earthquake of January 1994). The Vincent Thomas Suspension Bridge is one of them which was decided to be upgraded seismically in 1995. Several retrofit schemes were developed during this study on the Vincent-Thomas Suspension Bridge to reduce its longitudinal responses subjected to earthquake. Nazmy et al. [1] evaluated some of the proposed retrofit schemes in order to examine their effectiveness. Based on that paper, longitudinal viscous dampers were one of the major seismic retrofit measures proposed for this bridge. The other retrofit measure was to allow the formation of plastic hinges at the base of the tower shafts during severe seismic events in order to limit the longitudinal bending moment at the tower base to its plastic moment capacity. It was concluded that the vulnerabilities associated with longitudinal and vertical vibrations of the bridge deck could be reduced by installing longitudinal dampers and allowing plastic hinge formation at the tower base. Also, it has been concluded that installation of dampers 
in the side spans of the bridge was a very efficient scheme in reducing the seismic demand on the truss members in these spans.

All the above reviewed studies have considered the response reduction of the bridges in longitudinal direction, while the main objective of the present paper is to apply MR dampers to seismic control of suspension bridges in vertical direction. In the present paper, the Vincent-Thomas Suspension Bridge is chosen as a case study, and the mechanical behavior of the MR damper is presented by Normalized Bouc-Wen model with $2200 \mathrm{kN}$ capacity $[28,29]$. The damping force produced by an MR damper is mainly dependent on the input voltage to the damper which is regulated here using fuzzy logic controller. The analysis is performed in time domain.

On the other hand, the most challenging problem in this research was how to install the dampers on nodes of the bridge deck along the spans far from the towers. To overcome this, use of a "rigid truss" is proposed. In this novel method, a "rigid truss" is attached to the bottom of the bridge deck at any node of the bridge deck far from the towers, and then the MR damper can be installed between the bridge deck and free-end of the rigid truss. In order to evaluate the optimal performance of the MR dampers in reducing the vertical vibrations of the example bridge, different models have been proposed and optimized by trial and error method.

\section{Equation of motion of the bridge}

The detailed procedure to write the motion equation of suspension bridges is a complicated problem which is out of the scope of this paper. For more information on dynamic behavior of the suspension bridges, readers are referred to the studies performed by Abdel-Ghaffar and his co-authors [30]. The motion equation of these bridges can be written using finite element method and Hamilton's energy principles $[28,30]$. The main objective of the present study is to control the vertical vibration response of suspension bridges using $\mathrm{MR}$ dampers, and to find the optimal solutions for dampers' numbers and locations. To study the performance of the MR dampers in reducing the vertical response of these bridges, it is assumed that the bridge is subjected to vertical component of the earthquake acceleration transmitted to the bridge deck by the piers/ abutments. For numerical simulation of the bridge responses, 15 world-wide ground motion vertical accelerogrames, shown in Table 1, are used as the input excitations. The accelerogrames are chosen, such that a variety of Peak Ground Accelerations (PGAs), frequency content levels, and distance to fault rupture can be taken into account in the study. Static condensation [29] of the stiffness matrix is performed to eliminate the bending rotational degrees of freedom, and then the mass of each element is equally concentrated on its end nodes, resulting in a diagonal $n * n$ lumped mass matrix where $n$ is the total number of vertical degrees of freedom [4,28]. Finally, the equation of motion of the uncontrolled bridge can be written as follows [29]:

$$
[M]\{\ddot{u}(t)\}+[C]\{\dot{u}(t)\}+[K]\{u(t)\}=-[M]\{r\} \ddot{u}_{g}(t),
$$

Table 1. Earthquake accelerogrames considered in this study.

\begin{tabular}{cccccccc}
\hline No. & Earthquake & Station & Data & Ms & $\begin{array}{c}\text { Distance to } \\
\text { fault } \mathbf{( k m )}\end{array}$ & $\begin{array}{c}\text { PGA } \\
(\mathbf{g})\end{array}$ & $\begin{array}{c}\text { Data } \\
\text { reference }\end{array}$ \\
\hline 1 & Bam-Iran & Golbaf & $1382 / 10 / 5$ & 5.8 & 20 & 0.139 & NEIC \\
2 & Manjil-Iran & Roudbar & $1369 / 03 / 31$ & 7.4 & 13 & 0.217 & NEIC \\
3 & Ardakul-Iran & Torbate Heidarieh & $1389 / 05 / 8$ & 5.8 & - & 0.186 & NEIC \\
4 & Firoozabad-Iran & Abbar & $1383 / 03 / 8$ & 6.3 & - & 0.237 & EMSC \\
5 & Sarein-Iran & Astara & $1375 / 12 / 05$ & 6.1 & 55 & 0.191 & NEIC \\
6 & Gheshm-Iran & Bandar Abbas & $1384 / 09 / 6$ & 6.2 & 56 & 0.295 & IIEES \\
7 & Chi-Chi, Taiwan & CHY010 & $1999 / 09 / 20$ & 7.6 & 19.96 & 0.125 & CWB \\
8 & Loma Prieta & Hollister City Hall & $1989 / 10 / 18$ & 7.1 & - & 0.216 & USGS \\
9 & Imperial Valley & Centro Array \#1 & $1979 / 10 / 15$ & 6.9 & 15.5 & 0.056 & USGS \\
10 & Kocaeli, Turkey & Fatih & $1999 / 08 / 17$ & 7.8 & 64.5 & 0.128 & KOERI \\
11 & Erzincan, Turkey & Erzincan & $1992 / 03 / 13$ & 6.9 & 2.0 & 0.248 & - \\
12 & San Fernando & Hollywood Stor Lot & $1971 / 02 / 09$ & 6.6 & 21.2 & 0.136 & USGS \\
13 & Tabas, Iran & Tabas & $1978 / 09 / 16$ & 7.7 & - & 0.688 & - \\
14 & Northridge-Rinaldi & Pacoima Dam & $1994 / 01 / 17$ & 6.7 & 8.0 & 1.229 & CDMG \\
15 & Kobe & Takarazuka & $1995 / 01 / 16$ & 6.9 & 1.2 & 0.433 & CUE \\
\hline
\end{tabular}


where $[M],[C]$, and $[K]$ are the $n * n$ mass, damping, and condensed stiffness matrices of the bridge, respectively; $\{r\}$ is the location vector of ground acceleration, $\ddot{u}_{g}(t)$; the vectors $\{\ddot{u}(t)\},\{\dot{u}(t)\}$, and $\{u(t)\}$ are the acceleration, velocity, and displacement of the bridge vertical degrees of freedom, respectively, with respect to the ground [29]. It should be noted that in vertical vibration of suspension bridges, occurrence of plastic hinges in bridge deck/towers is not a matter of concern; therefore, no material non-linearity is considered in Eq. (1); on the other hand, due to the fact that the problem under investigation is too complicated, the probable effects cannot be judged. However, dynamic behaviors of the main cables exhibit a high geometric non-linearity which has been considered in Eq. (1) to some extent [30].

Damping matrix of the bridge is also obtained by Rayleigh method using mass and stiffness matrices as follows [29]:

$$
[C]=a_{0}[M]+a_{1}[K],
$$

in which the proportionality coefficients $a_{0}$ and $a_{1}$ are calculated from the following equation:

$$
\frac{1}{2}\left[\begin{array}{cc}
\frac{1}{\omega_{i}} & \omega_{i} \\
\frac{1}{\omega_{j}} & \omega_{j}
\end{array}\right]\left\{\begin{array}{l}
a_{0} \\
a_{1}
\end{array}\right\}=\left\{\begin{array}{l}
\xi_{i} \\
\xi_{j}
\end{array}\right\}
$$

where $\omega_{i}$ and $\omega_{j}$ are the natural frequencies of the $i$ th and $j$ th modes of the bridge. In this study, $i$ is chosen as the first and $j$ as the 24th vibrational mode of the bridge [4,28]; $\xi$ is the ratio of structural damping to its critical value, which is assumed to be the same for both modes and about $1 \%$.

In this paper, the equation of motion of the bridge is transformed to state-space format [31] and solved utilizing the Simulink Toolbox of the MATLAB software; and in order to reduce the complexity of the problem and its mathematical expressions, the generalized modal coordinates are used as the state coordinates. Moreover, for the example bridge chosen in this study, using trial and error method, it is shown that the first 7 modes of vibration are sufficient to obtain accurate results [32].

The equation of motion of a bridge controlled by MR dampers, in general, can be written as follows [33]:

$$
\begin{aligned}
{\left[M^{*}\right]\{\ddot{u}(t)\} } & +\left[C^{*}\right]\{\dot{u}(t)\}+\left[K^{*}\right]\{u(t)\}=[D]\{f\} \\
& -\left[M^{*}\right]\{r\} \ddot{u}_{g}(t),
\end{aligned}
$$

where $\left[M^{*}\right],[C]$, and $[K]$ are the mass, damping, and condensed stiffness matrices of the controlled bridge, respectively; $[D]$ is the matrix of the locations on which the MR dampers are installed; and $\{f\}$ is the vector of control force imposed by the MR dampers to the

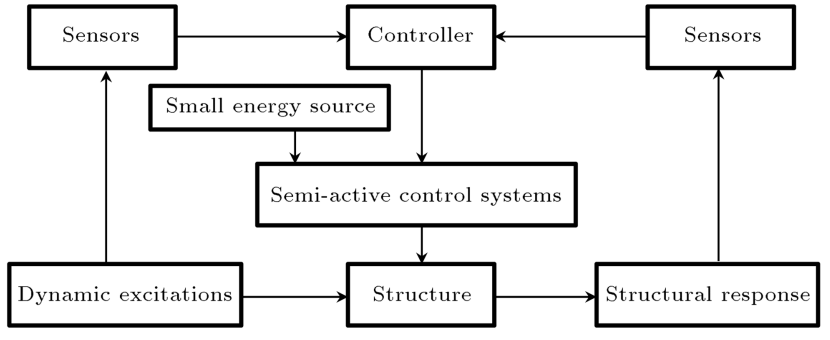

Figure 1. Schematic diagram of semi-active control system.

bridge deck. Figure 1 shows the schematic diagram of semi-active control system in a real structure. In the current study, the sensors' input data are obtained from the simulations results.

\section{Description of MR damper system}

The mechanical model of the MR damper must be chosen, such that it can adequately characterize the intrinsic non-linear behavior of the damper. In this regard, a number of mechanical models have been recently proposed by several researchers [9,23-26,34]. In the present study, a large-scale MR damper with $2200 \mathrm{kN}$ capacity based on normalized Bouc-Wen model is used for which the parameter identification has been conducted by Bahar et al. [23]. The mechanical model of this damper is shown in Figure 2. The equations governing the force $f(0)$ exerted by this model of damper to the bridge are as follows [23]:

$$
\begin{aligned}
& \begin{aligned}
f(x(t), & \dot{x}(t), w(t))=k_{x}(v) x(t)+k_{\dot{x}}(v) \dot{x}(t)+k_{w} w(t), \\
\dot{w}(t)= & \rho(v)\left\{\dot{x}(t)-\sigma(v)|\dot{x}(t)||w(t)|^{\eta(v)-1} w(t)\right. \\
& \left.+(\sigma(v)-1) \dot{x}(t)|w(t)|^{\eta(v)}\right\},
\end{aligned} \\
& k_{x}(v)=k_{x}, \\
& k_{\dot{x}}(v)=k_{\dot{x} a}+k_{\dot{x} b} v,
\end{aligned}
$$

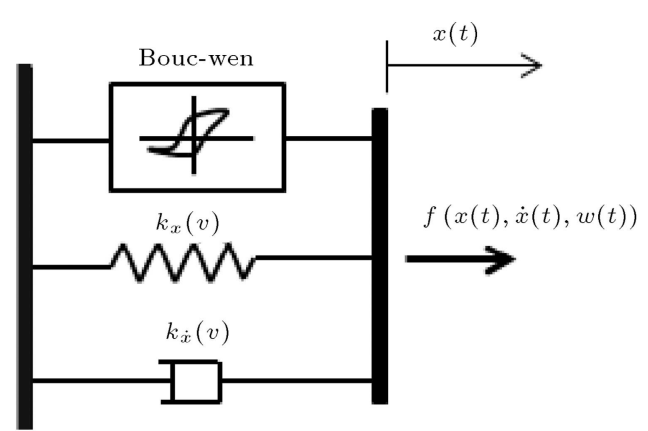

Figure 2. Mechanical model of MR damper used in this study. 


$$
\begin{aligned}
& \eta(v)=\eta_{a}+\eta_{b} \exp (-13 v), \\
& \rho(v)=\rho_{a}+\rho_{b} \exp (-14 v), \\
& \sigma(v)=\sigma_{a}+\sigma_{b} \exp (-14 v), \\
& K_{w}(v)=\left\{\begin{array}{c}
K_{w 1}+K_{w 2} v^{1.15}, \\
K_{w 3}+K_{w 4} \sin \left(\frac{\pi(v-0.3)}{0.8}\right) \\
+K_{w 5} \sin \left(\frac{3 \pi(v-0.3)}{0.8}\right), \\
0.3 \leq v \leq 0.7 \\
K_{w 6}+K_{w 7} v+K_{w 8} v^{3} \\
+K_{w 9} v^{5},
\end{array} \quad 0.7 \leq v\right.
\end{aligned}
$$

where the term $k_{x}(v) x(t)$ represents a linear elastic force; $f(0)$ is the output force of the MR damper; $x(t), \dot{x}(t)$, and $v$ are displacement, velocity, and voltage inputs, respectively. The state variable $w(t)$ has no physical meaning; so, it should be calculated mathematically from Eq. (6). The other parameters including $k_{x}, k_{\dot{x} a}, k_{\dot{x} b}, \eta_{a}, \eta_{b}, \rho_{a}, \rho_{b}, \sigma_{a}, \sigma_{b}, k_{w 1}, k_{w 2}, \ldots, k_{w 9}$ are to be determined by the experimental test for which the numerical values used in this study are given in Table 2 .

\section{Numerical study}

In this paper, semi-active control system is used to mitigate the seismic vertical response of suspension bridges

Table 2. The parameters of the large-scale normalized MR damper used in this study.

\begin{tabular}{cc}
\hline Parameter & Value \\
\hline$K_{x}$ & 207 \\
$K_{\dot{x}, a}$ & 89.64 \\
$K_{\dot{x}, b}$ & 292 \\
$\rho_{a}$ & 648.95 \\
$\rho_{b}$ & -3.86 \\
$\eta_{a}$ & 1.44 \\
$\eta_{b}$ & 0.02 \\
$\sigma_{a}$ & 0.76 \\
$\sigma_{b}$ & 0.009 \\
$k_{w 1}$ & 55.38 \\
$k_{w 2}$ & 2270 \\
$k_{w 3}$ & 619.85 \\
$k_{w 4}$ & 387.34 \\
$k_{w 5}$ & 18.42 \\
$k_{w 6}$ & -87.52 \\
$k_{w 7}$ & 2665 \\
$k_{w 8}$ & -3054.7 \\
$k_{w 9}$ & 1545.5 \\
\hline
\end{tabular}

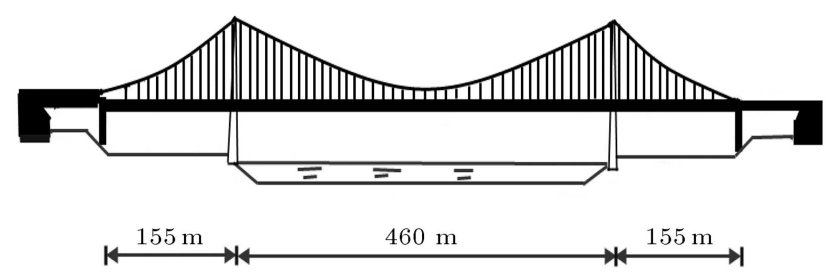

Figure 3. General view of vincent-Thomas suspension bridge.

using MR dampers. The Vincent-Thomas suspension bridge, shown in Figure 3, is chosen for numerical study. This bridge was constructed to connect San Fernando to the Terminal Island at the port of Long Beach to the south of Los Angeles, California. Its superstructure consists of a $460 \mathrm{~m}$ center span and two $155 \mathrm{~m}$ side spans. There are two towers with the height of $102 \mathrm{~m}$, and sag of the main cable in the center of the main span is $45.72 \mathrm{~m}[1,30]$. The weight of the deck and the two main cables are about $52438 \mathrm{~N} / \mathrm{m}$ and $12390 \mathrm{~N} / \mathrm{m}$, respectively.

The cross area of each main cable is almost $780 \mathrm{~cm}^{2}$ and the initial tension due to dead loads in each cable is $30038 * 10^{3} \mathrm{~N}[1,30]$. The bridge has been simulated by many researchers in the past, and the stiffness and mass matrices are available in [28]. The finite element model of the bridge is shown in Figure 4. According to this figure, for finite element analysis of the bridge, 11 elements in each side span and 28 elements in the center span are considered $[1,30]$. The bridge deck is considered as a simply supported beam between the towers, connected by several hangers to the main cables. The end connections of the bridge girders to the towers are assumed to be hinged. In finite element model of the bridge, two nodded beam elements with two degrees of freedom at each node, vertical displacement, and bending rotation are considered (Figure 4(b)) [1,4,28,30]. The first 6 modal frequencies and mode shapes of the bridge are emerged in Figure 5 [28]. A more detailed description of the bridge can be found in Abdel-Ghaffar [30].

As illustrated above, in this study, semi-active control system utilizing MR dampers is used to reduce the seismic vertical response of suspension bridges. For this purpose, different control models, in point of MR dampers installation view, are investigated to achieve the optimal model of the control system to get maximum reduction in bridge responses. The main aim of these models is to optimize the number and location of the dampers. The first model that comes to mind is to install MR dampers between the stiffening truss of bridge deck and towers, but due to low displacement that is expected to happen near the towers, this option sounds not to be more appropriate. Therefore, the problem of how to install the dampers along the bridge span at any node far from the towers should be solved. For this purpose, firstly, different models have been 

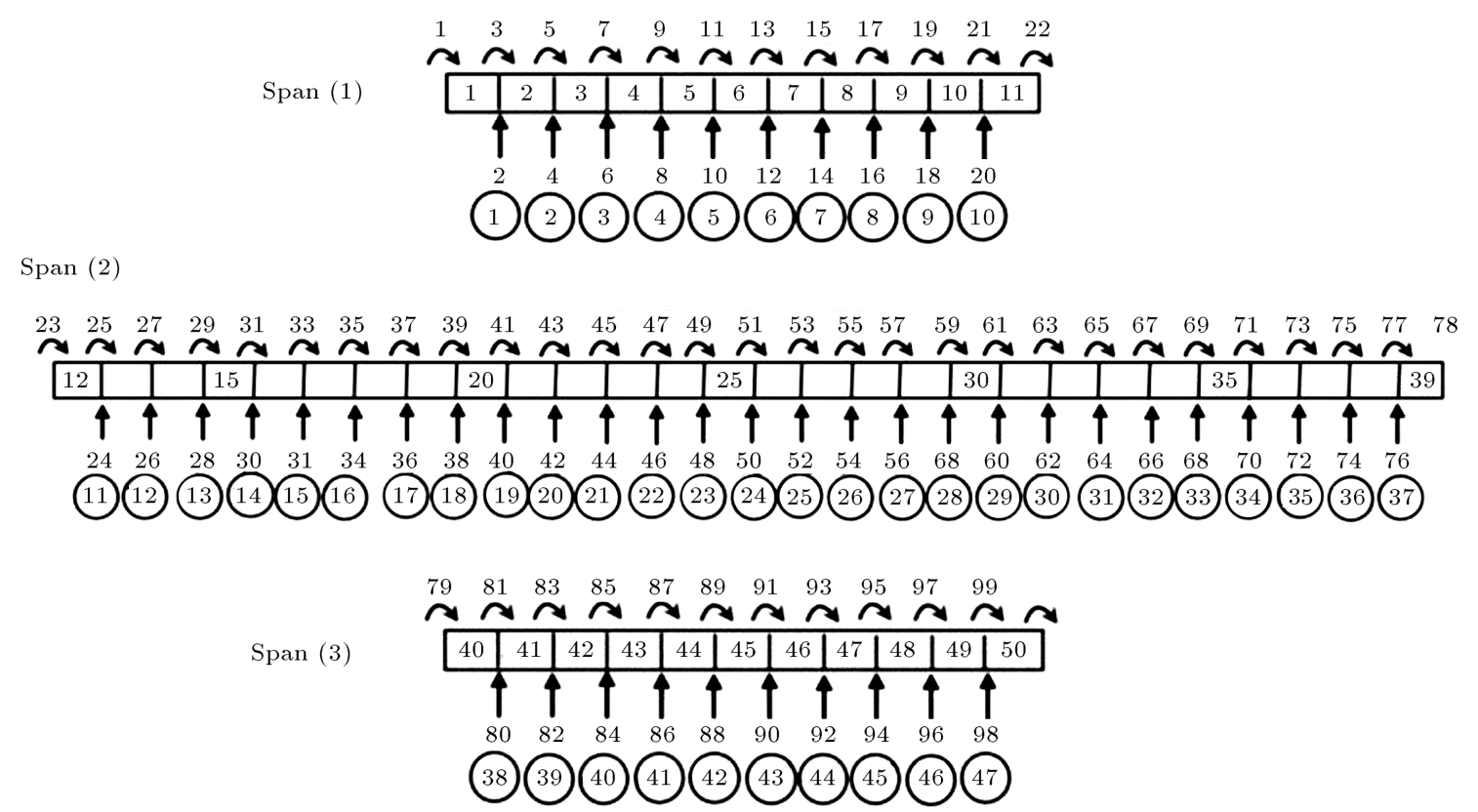

(a)

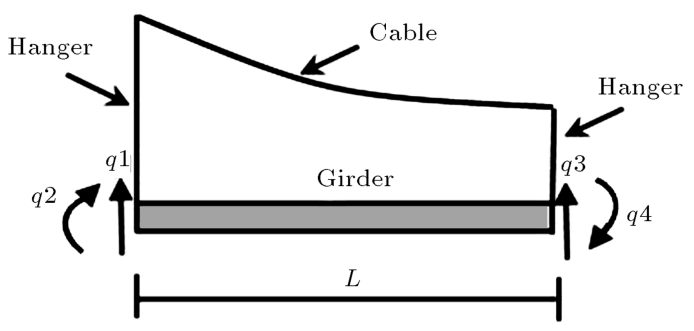

(b)

Figure 4. (a) Elements and node numbers in each span. (b) One finite element of the bridge, showing the degrees of freedom.

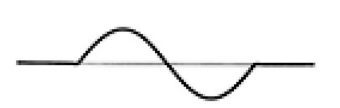

Mode $1 \quad f=0.19 \mathrm{~Hz}$

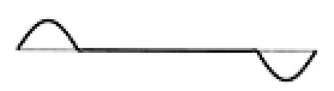

Mode $3 \quad f=0.34 \mathrm{~Hz}$

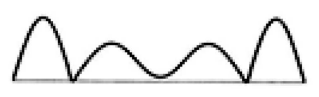

Mode $5 \quad f=0.46 \mathrm{~Hz}$

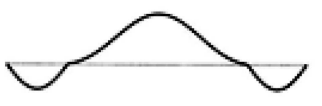

Mode $2 f=0.21 \mathrm{~Hz}$

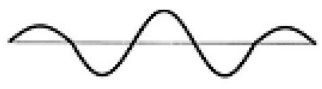

Mode $4 \quad f=0.35 \mathrm{~Hz}$

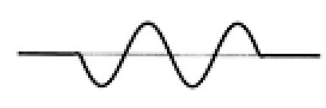

Mode $6 \quad f=0.55 \mathrm{~Hz}$

Figure 5. Vincent-Thomas suspension bridge's first 6 mode shapes and frequencies.

proposed to install the dampers at the nodes far from towers, and then the bridge responses are calculated under the application of the earthquake accelerogrames given in Table 1 to evaluate the performance of these models. If a proposed model has an appropriate operation, then its performance is optimized for the number and location of the dampers.

Herein, it should be mentioned that in this research, semi-active control of the suspension bridges is studied through fuzzy logic, and in particular, two schemes of passive off and passive on have been investigated. There are a vast number of parameters, including input and output variables of fuzzy logic, membership functions, fuzzy rules, and the number and location of dampers, which make the investigation sophisticated. To reduce the complexity, first, the number and location of dampers have been optimized through passive off and passive on cases. After that, the optimized models have been studied for semi-active control scheme. It is found that although semi-active control performs in an excellent way to reduce the vertical vibrations of the system; in most of the times, the results are the same as the passive on scheme, and fuzzy controller seems unable to perform better than the passive on scheme despite a lot of striving by trial and error method. In spite of the fact that fuzzy logic is overwhelmingly efficient in reducing the power source, it should be noted that the power source is not an important matter when it comes to MR dampers. 
Therefore, due to the massive details and results related to the fuzzy logic controller and in order to keep the paper length short, just the displacement results of some particular cases of passive off and passive on schemes are discussed in the present paper.

Finally, among the different models studied in this investigation, 3 models are chosen for optimization and presented in the following.

Model 1: Installation of $M R$ dampers along the bridge span using a TMD system.

In the first proposed model, to install MR dampers, as shown in Figure 6, a Tuned Mass Damper (TMD) system is used to install the dampers to the bottom of the bridge deck far from the towers. The results obtained from this model indicate that in spite of high complexity of this method, it is not appropriate. This model is not only unable to decrease the bridge responses, but also it increases them. The complexity of this model is due to the large number of its unknowns including the amount of mass of the TMD and stiffness of the spring, in addition to the number of MR dampers and their locations.

Some of different schemes of this model (Case 1 to Case 5), in which only the location and number of dampers vary along the bridge span, are given in Figure 7. The controlled and uncontrolled averaged maximum displacement responses of the bridge evaluated for the Case 1 of Figure 7 are presented in Figure 8.

It can be seen from the Figure 8 (b) that the bridge response at some node points is highly increased, showing that use of the TMD for installing the MR damper along the bridge span does not provide acceptable reduction in bridge responses. In this case, the TMD mass and its spring stiffness are chosen about $10^{6} \mathrm{~kg}$ and $3 * 10^{7} \mathrm{~N} / \mathrm{m}$, respectively. The other cases of this model, shown in Figure 7 , also show the same trend in reducing the bridge responses. Therefore, it is finally concluded that this model is not appropriate for this example bridge.

It should be noted that many other cases (not shown here) have been studied in this model by changing the values of mass and stiffness of the TMD and its location, but none of them showed appropriate results. Moreover, it is noted that in this study, semiactive performance of the MR dampers is studied, but

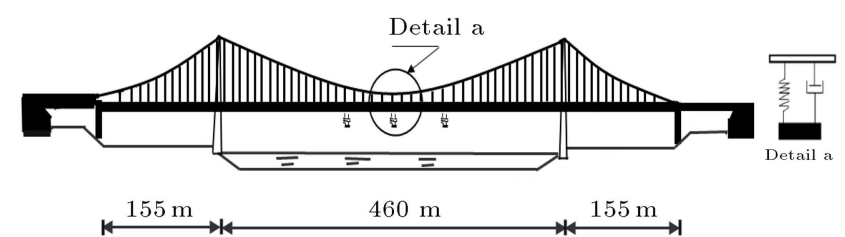

Figure 6. Installation of MR dampers at nodes far from towers using TMD.

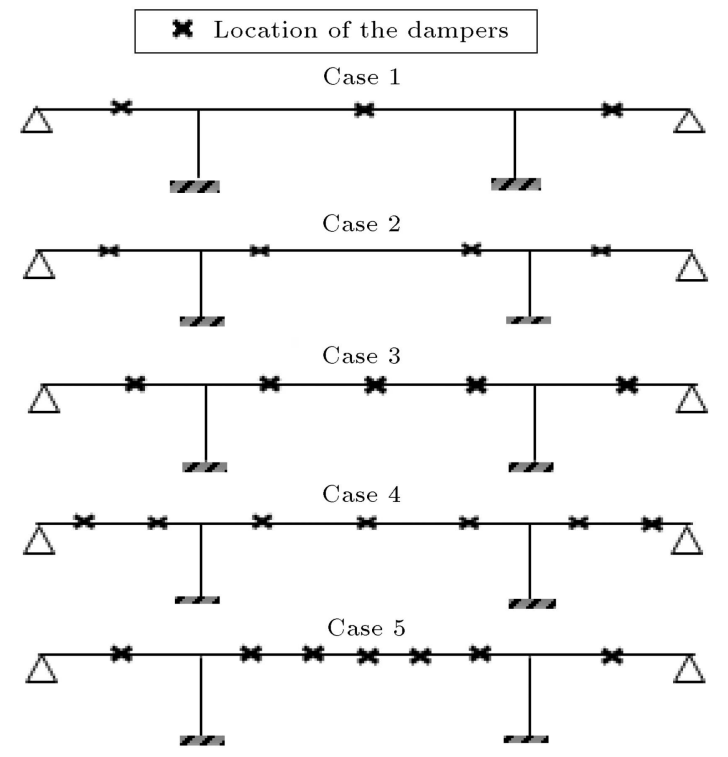

Figure 7. Some different schemes investigated in Model 1 by trial and error method.

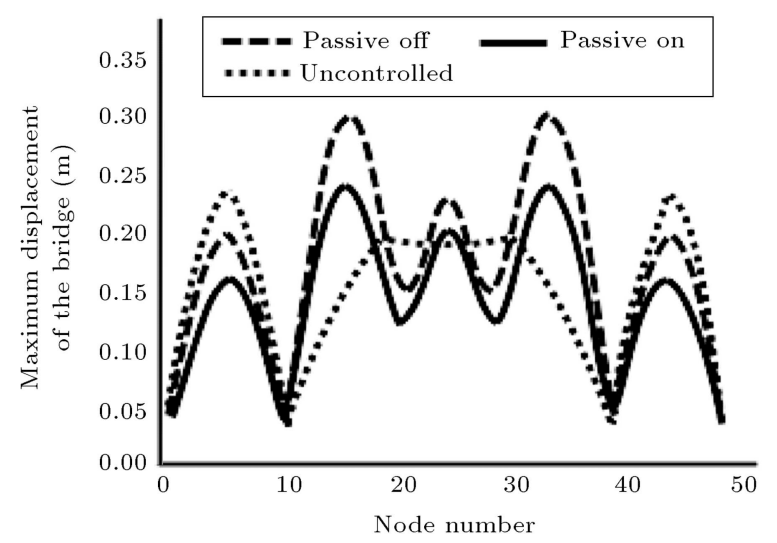

(a)

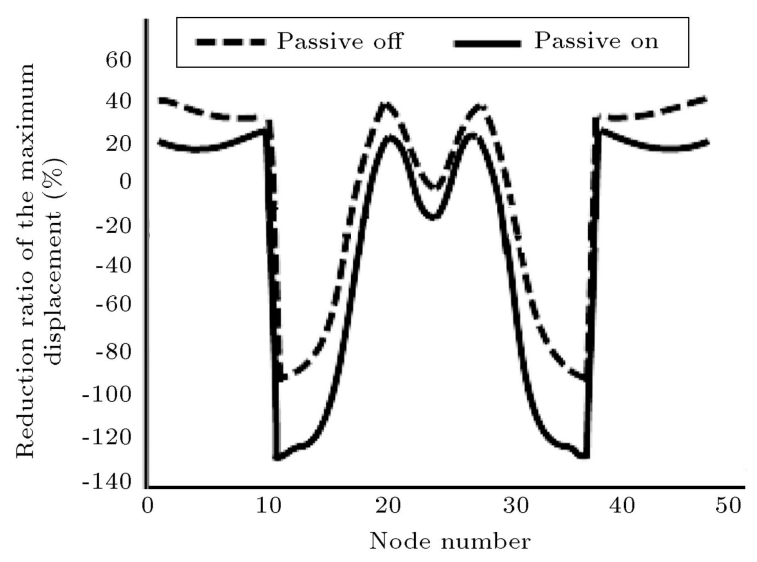

(b)

Figure 8. Comparison of the uncontrolled and controlled responses in Case 1 of Model 1 for voltage of zero (passive off) and maximum voltage (passive on): (a) Averaged maximum displacements, and (b) response reduction ratios. 
due to its improper operation, only the extreme results (passive on and passive off) are presented here.

Model 2: Installation of $M R$ dampers near the towers.

After investigating the performance of the Model 1 and concluding its inability in reducing the bridge responses, it is decided to install the dampers between the towers and bridge deck as shown in Figure 9. In this model, there is no need for the TMD system; therefore, the number of the dampers is limited to what can be installed near the towers and piers (or abutments). It should be highlighted that increasing the number of dampers may not always lead to more response reduction. It is due to high non-linearity and high flexibility of the bridge. As a result, some of the dampers in this study are used with the capacity of $1100 \mathrm{kN}$, called scaled dampers, discussed by Rodriguez [25].

In this model, dynamic characteristics of the controlled bridge and the uncontrolled one are the same in the equation of motion. Also, as shown in Figure 10, different cases here (Cases 1 to 6), which differ in number, location, and the capacity of the dampers (2200 $\mathrm{kN}$ or $1100 \mathrm{kN}$ dampers), have been investigated by trial and error method to find the optimal case. After comparing the reduction ratios on bridge responses, the optimal case is evaluated for which the configuration of the dampers is shown in Figure 11. In this optimal case, total number of 4 dampers are installed between the deck and main towers as follows: two dampers with the capacity of $2200 \mathrm{kN}$ between the towers and nodes number 10 and 38; two dampers with the capacity of $1100 \mathrm{kN}$ between the towers and nodes number 11 and 37 of the bridge, as shown in Figure 11 (nodes number are given in Figure 4).

In the next step, the bridge is analyzed for the optimal case of damper installation, shown in Figure 11, under the 15 earthquake accelerogrames of Table 1 , and then the ensemble average of maximum displacement responses of the bridge for these 15 accelerogrames are calculated and compared in Figure 12. As it can be seen from the figure, the reduction ratio of the bridge average maximum displacements is between $5-15 \%$ in passive off control (voltage is zero), and it is between $10-62 \%$ in passive on control (voltage is maximum). The minimum reduction happens in the middle of the center span, and the maximum reduction happens at the nodes on which MR dampers are installed. The most important problem of this model is its inability in reducing the displacements of the middle of the center span, which is solved in Model 3 and explained in the next section.

Model 3: Installation of $M R$ dampers at any desired node using a rigid truss (as a novel method).

One of the most challenging problems in this research, as mentioned before, is how to install the MR
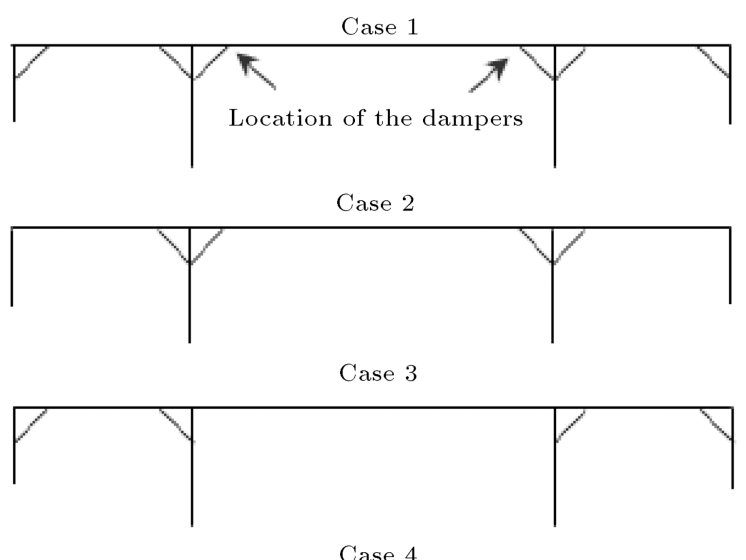

Case 4

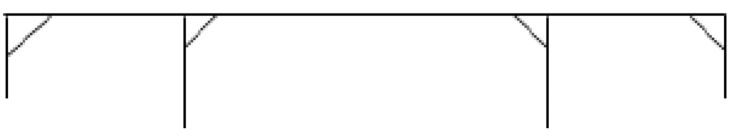

Case 5

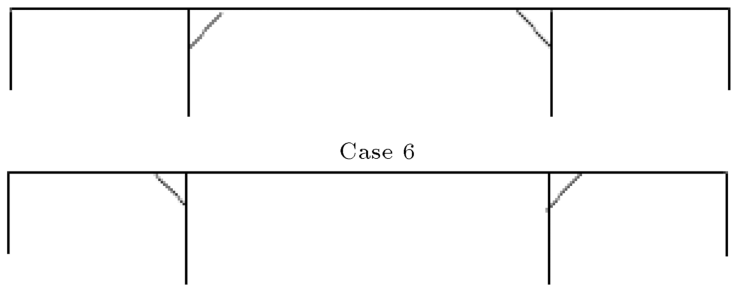

Figure 10. Some cases of different schemes investigated in Model 2 by trial and error method.

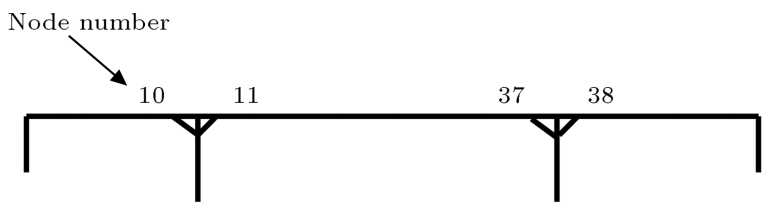

Figure 11. Optimal installation configuration of the MR dampers in Model 2.
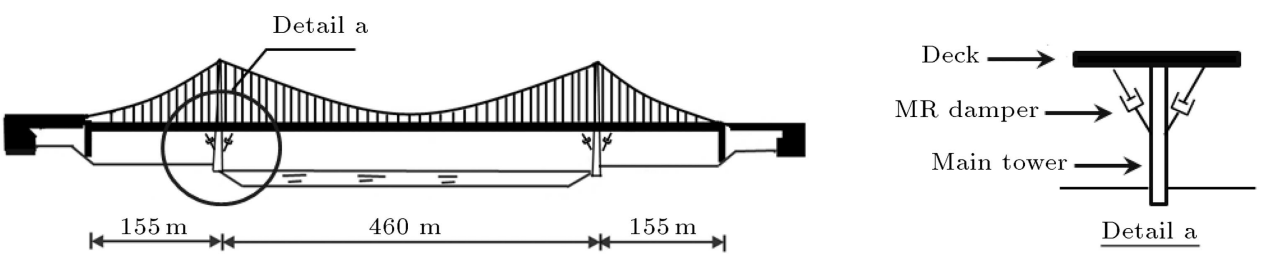

Figure 9. Installation of MR dampers on the bridge deck in Model 2. 


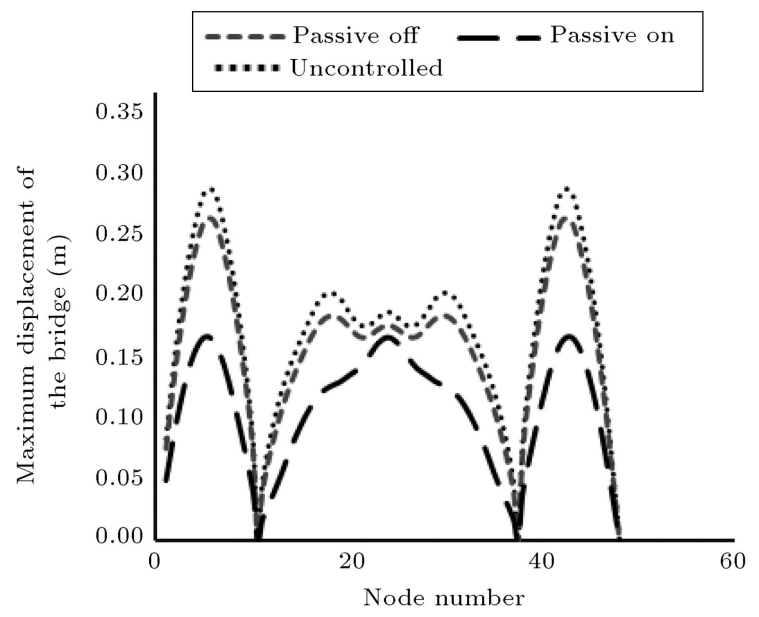

(a)

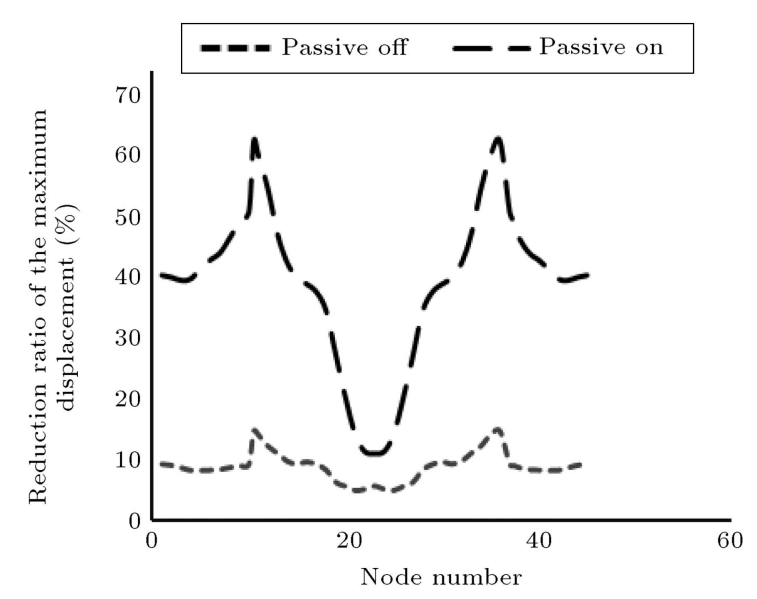

(b)

Figure 12. Comparison of the bridge maximum uncontrolled displacements with those controlled by passive off and passive on systems: (a) The ensemble average of maximum displacements for 15 accelerogrames, and (b) reduction ratio of the averaged maximum displacements. dampers at a node of bridge deck far from the towers. The first idea offered for this purpose (use of the TMD as explained in Model 1) was not appropriate, and the second one operated well, although it was not expected. As it is seen in the previous section, the Model 2 is not able to reduce the bridge responses at the middle of the center span. To overcome this drawback, Model 3 is proposed in which, as shown in Figure 13, the MR dampers are installed either between the bridge deck and free-end of a rigid truss at any node far from the towers or between the bridge deck and towers described in Model 2. According to the Figure 13-Detail b, the forces produced by the MR damper, installed between the bridge deck and the rigid truss, will be transferred to the bridge deck by elements of truss (forces F1, F2, and F3 in the figure). It should be noted that, as it can be seen from the figure, the rigid truss is attached to the bridge deck at points $\mathrm{A}, \mathrm{B}$, and $\mathrm{C}$, among which only the point $B$ is considered as a node in the finite element model of the bridge deck (see Figure 4). Therefore, in the present study, the forces F1 and F3 cannot be directly inserted into the bridge equation of motion, and the resultant of these forces is considered in the model equation. Thus, some moments are probably produced during transformation of the MR dampers forces to the deck by the truss. If the dampers are installed symmetrically, these moments will be neutralized; otherwise, they should be considered in the simulation. In this study, because of the limitation in the finite element model, this effect is neglected. From the results of the bridge controlled responses, it is found that without considering these extra moments, asymmetric results are a few better than those of the symmetric ones. In order to account for the effects of these extra moments, there are some strategies among which the first one is increasing the number of nodes in the finite element model of the bridge, such that all the

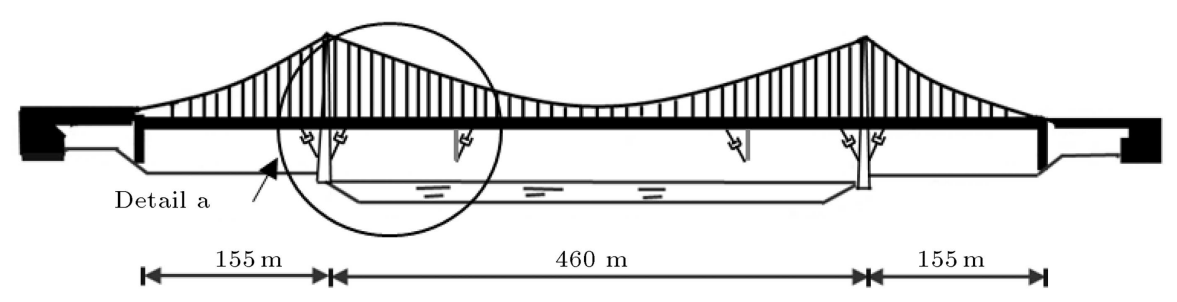

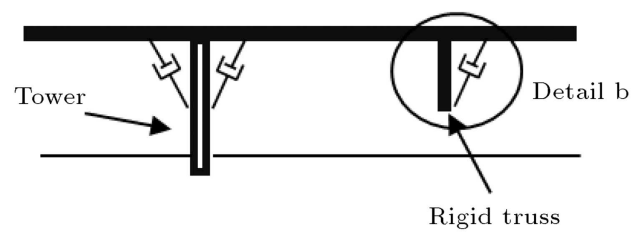

$\underline{\text { Detail a }}$

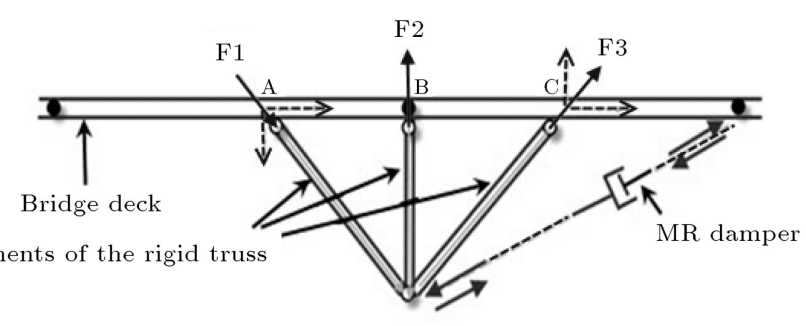

Detail b

Figure 13. Installation details of the MR dampers in Model 3. 


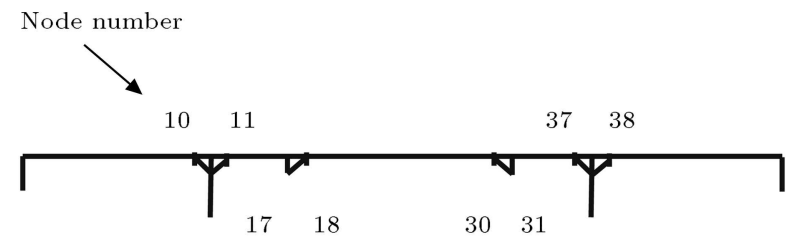

Figure 14. Optimal installation configuration of the MR dampers in Model 3 (Scheme 3-1 with 6 dampers).

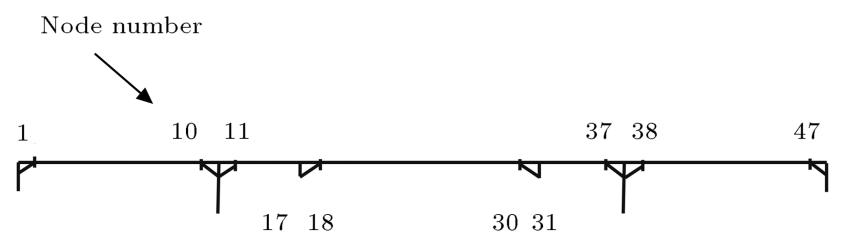

Figure 15. Optimal installation configuration of the MR dampers in Model 3 (Scheme 3-2 with 8 dampers).

forces F1, F2, and F3 could be directly considered in the equation of motion. The second one is neglecting the extra moments (used in this study); the last one is symmetric installation of the dampers instead of asymmetric without considering the economic issues. In this paper, the results of the asymmetric model also have been figured. Here also, different schemes have been also investigated to achieve the optimal number, location, and capacity of dampers using trial and error method. Finally, 2 schemes (Schemes 3-1 and 3-2), shown in Figures 14 and 15, are suggested as the optimal ones.

Figures 16 and 17 show the comparison between averaged values of the controlled and uncontrolled vertical maximum displacement response of the example bridge for Schemes 3-1 and 3-2, respectively. Figures 16(a) and 17(a) show the ensemble average of the maximum displacement of the bridge subjected to 15 earthquake accelerogrames of Table 1; Figure 16(b) and 17 (b) show the reduction ratio of this response quantity. It is clear from the figures that the performance of Scheme 3-1, in which 6 dampers are used, is better than Scheme 3-2 in the middle of the center span, while in the side spans, Scheme 3-2 works better. Moreover, performance of both schemes in Model 3 is much better than Model 2.

In passive off (voltage is zero), the reduction ratio of the average maximum displacement is about $10-20 \%$, while in passive on (voltage is maximum), this value is about $30-70 \%$. The minimum reduction happens in the middle of the center span, and the maximum reduction happens at the nodes at which the MR dampers are installed.

The results of Scheme 3-2, in which 8 dampers have been used, are shown in Figure 17. The reduction ratio of the average maximum displacement is about $10-20 \%$ in passive off (voltage is zero), about $25-70 \%$ in passive on (voltage is maximum), and almost the same as Scheme 3-1 in passive off control. Furthermore, the

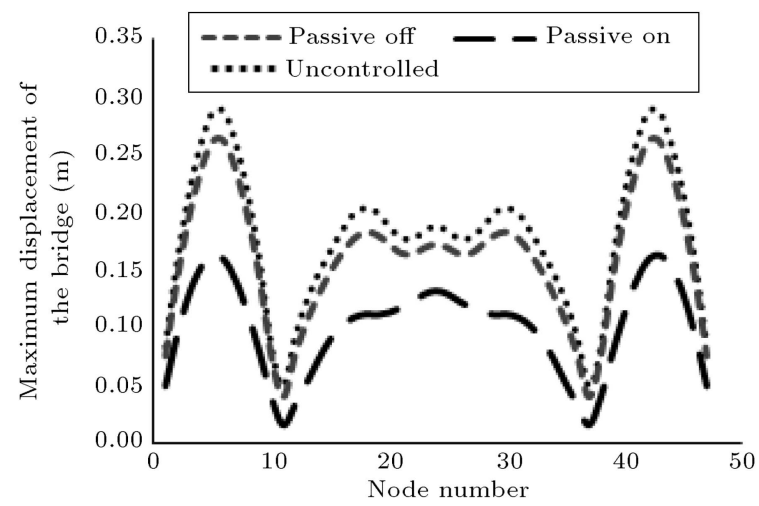

(a)

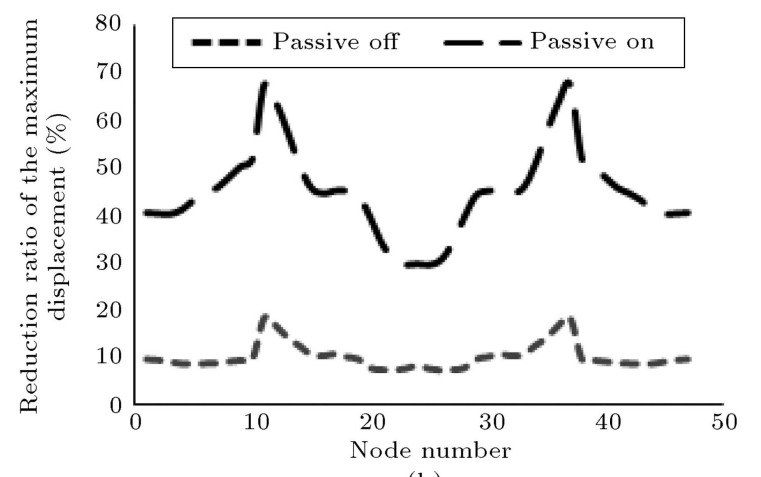

(b)

Figure 16. Comparison of the uncontrolled and controlled responses in Model 3 with 6 dampers for voltage of zero (passive off) and maximum voltage (passive on) for Scheme 3-1: (a) Ensemble average of the maximum displacements, and (b) response reduction ratios.

reduction in passive on is more than Scheme 3-1 for the suspended side spans, but it performs between Model 2 and Scheme 3-1 for the center spans.

\section{Conclusions}

Seismic vibration control of suspension bridges in horizontal direction is well studied and reported in the literature, but no research is reported on this issue in vertical direction. In this paper, the performance of semi-active control of vertical vibration of suspension bridges subjected to earthquake using MR dampers is discussed. The Vincent-Thomas suspension bridge located in Los Angeles, U.S.A., is chosen as a case study, and 15 worldwide major earthquake accelerogrames are used in the numerical analyses. The main challenging problem in this study was how to install the MR damper at a node of bridge deck far from the towers. To solve it, different models have been suggested and optimized by trial and error method, and the optimal location and number of the dampers are evaluated. Finally, 3 models have been proposed as the appropriate ones. In the first model, Model 1, the MR dampers are installed along the bridge span by use of a TMD system. In the second one, Model 2, the MR dampers are 


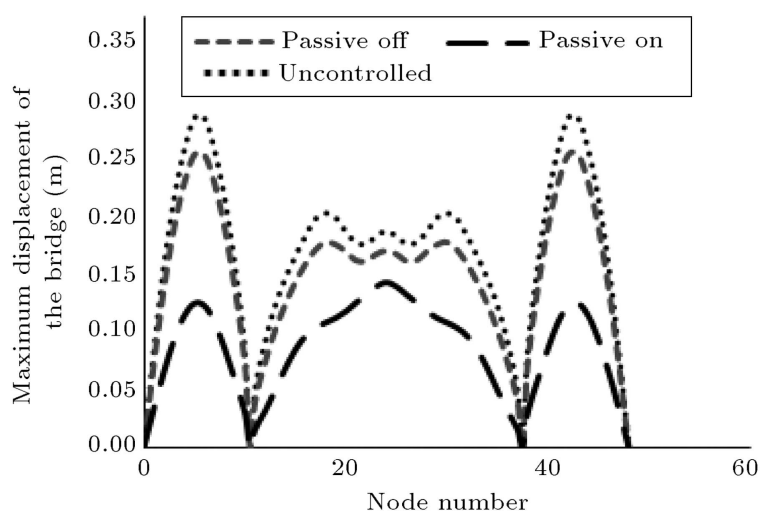

(a)

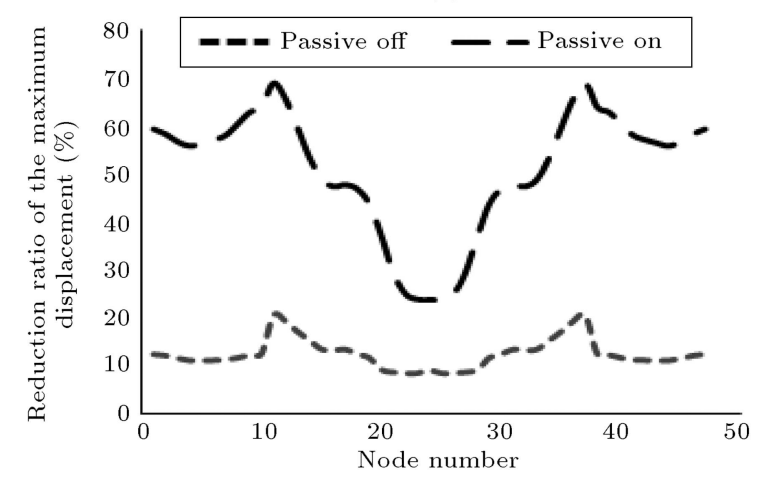

(b)

Figure 17. Comparison of the uncontrolled and controlled responses in Model 3 with 8 dampers and for voltage of zero (passive off) and maximum voltage (passive on) for Scheme 3-2: (a) Ensemble average of the maximum displacements, and (b) response reduction ratios.

installed only between the towers and the bridge deck. In the third one, Model 3, a novel rigid truss is used to install the MR dampers between free-end of the truss and any desired node of the bridge deck, in addition to the dampers installed between the towers/or abutments and bridge deck. In Model 2, 4 dampers are installed between the towers and bridge deck. In Model 3, two schemes (Schemes 3-1, and 3-2) are proposed as the optimal ones which differ in the location and number of the dampers. The novel method of using rigid truss is proposed in Model 3 to install the MR dampers at the nodes of bridge deck far from the towers; the optimal numbers of the MR dampers have been evaluated as 6 and 8 dampers in Schemes 3-1 and 3-2, respectively. From the results of this numerical study, it is found that the use of a TMD system in such problems is useless; however, the other proposed models, Models 2 and 3 (Schemes 3-1 and 3-2), are successful in reducing the vertical vibration of the example bridge. The most reduction ratio of the center span relates to Scheme 3-1 of Model 3, and those of the side spans belong to Scheme 3-2 of this model. Finally, it should be highlighted that although the reduction ratio has its least value in Model 2, it is introduced as an appropriate model due to the fact that it has the least number of dampers. In both of Models 2 and 3, the maximum reduction of the bridge vertical displacement is obtained at the nodes at which the MR dampers are installed.

\section{References}

1. Nazmy, S.A., Abdel-Ghaffar, A.M. and Masri, S.F. "Seismic retrofit of the vincent-thomas suspension bridge", Emirates J. Eng. Res., 9(2), pp. 35-43 (2004).

2. Hansen, H.I. and Thoft-Christensen, P. "Active flap control of long suspension bridges", J. Struct. Control, 8(1), pp. 33-82 (2001).

3. Jing, C., Xiao-zhen, L. and Shi-zhong, Q. "Active control research of cable-stayed bridge subject to seismic excitation", Bridg. Constr., 3(1), pp. 10-11 (2002).

4. Pourzeynali, S. and Esteki, S. "Optimization of the TMD parameters to suppress the vertical vibrations of suspension bridges subjected to earthquake excitations", Int. J. Eng. Trans. B Appl., 22(1), pp. 23-34 (2009).

5. Chung, L.L., Wu, L.Y., Huang, H.H., Chang, C.H. and Lien, K.H. "Optimal design theories of tuned mass dampers with nonlinear viscous damping", Earthq. Eng. Eng. Vib., 8(4), pp. 547-560 (2010).

6. JianJun, J. and HongBo, Z. "Influence of nonlinear viscous damper on earthquake response of suspension bridge", J. Urban Loads Bridg. Flood Control, 11(2), pp. 99-102 (2004).

7. Sadek, F., Mohrez, B. and Lew, H.S. "Single and multiple-tuned liquid column dampers for seismic applications", J. Earthq. Eng. Struct. Dyn., 27(5), pp. 439-463 (1998).

8. Domaneschi, M. "Simulation of controlled hysteresis by the semi-active Bouc-Wen model", Comput. Struct., 106-107, pp. 245-257 (2012).

9. SpencerJr, B.F., Dyke, S., Sain, M. and Carlson, J. "Phenomenological model of a magnetorheological damper", ASCE J. Eng. Mech., 123(3), pp. 230-238 (1997).

10. Domaneschi, M. "Feasible control solutions of the ASCE benchmark cable-stayed bridge", Struct. Control Heal. Monit., 17(6), pp. 675-693 (2010).

11. Dyke, S.J., Caicedo, J.M., Turan, G., Bergman, L.A. and Hague, S. "Phase I benchmark control problem for seismic response of cable-stayed bridges", J. Struct. Eng., 129(7), pp. 857-872 (2003).

12. Alapati. A., Lakshmi, V. and Saha, P. "Review of the performance of semi-active control systems for benchmark cable-stayed bridge", Int. J. Earth Sci. Eng., 4(6), pp. 720-725 (2011).

13. Agrawal, A.K., Yang, J.N. and He, W.L. "Applications of some semiactive control systems to benchmark cable-stayed bridge", J. Struct. Eng., 129(7), pp. 884894 (2003).

14. Jung, H.-J., Spencer, B.F. and Lee, I.W. "Benchmark control problem for seismically excited cable-stayed 
bridges using smart damping strategies", in IABSE Conference, Seoul, Korea, pp. 40-47 (2001).

15. Moon, S.J., Bergman, L.A. and Voulgaris, P.G. "Sliding mode control of cable-stayed bridge subjected to seismic excitation", J. Eng. Mech., 129(1), pp. 71-78 (2003).

16. Carlsosn, J.D. and Spencer Jr, B.F. "MagnetoRheological fluid dampers for semi-active seismic control", in Proc. of the 3rd Int. Conf. on Motion and Vibr. Control, pp. 35-40 (1996).

17. Dyke, SJ., Spencer, B.F., Sain, M.K. and Carlson, J.D. "Modeling and control of magnetorheological dampers for seismic response reduction", Smart Mater. Struct., 5(5), pp. 565-575 (1996).

18. Jung, H.J., Spencer, B.F. and Lee, I.W. "Control of seismically excited cable-stayed bridge employing magnetorheological fluid dampers", J. Struct. Eng., 129(7), pp. 873-883 (2003).

19. Shuisheng, C. "Magneto-rheological(MR) dampers semi-active control of earthquake response for elevated bridge", J. Chang. Univ. Sci. Ed., 23(6), pp. 40-43 (2003).

20. Ok, S.Y., Kim, D.S., Park, K.S. and Koh, H.M. "Semiactive fuzzy control of cable-stayed bridges using magneto-rheological dampers", Eng. Struct., 29(5), pp. $776-788$ (2007).

21. Yang, M., Chen, Z. and Hu, J. "Investigations concerning seismic response control of self-anchored suspension bridge with MR dampers", Front. Archit. Civ. Eng., China, 2(1) pp. 43-48 (2008).

22. Yang, M.G., Chen, Z.Q. and Hua, X.G. "An experimental study on using MR damper to mitigate longitudinal seismic response of a suspension bridge", Soil Dyn. Earthq. Eng., 31(8), pp. 1171-1181 (2011).

23. Bahar, A., Pozo, F., Acho, L., Rodellar, J. and Barbat, A. "Parameter identification of large-scale magnetorheological dampers in a benchmark building", Comput. Struct., 88(3-4), pp. 198-206 (2010).

24. Ikhouane, F. and Rodellar, J., Systems with Hysteresis: Analysis, Identification and Control Using the BoucWen Model, John Wiley \& Sons (2007).

25. Rodríguez, A., Pozo, F., Bahar, A., Acho, L., Vidal, Y. and Rodellar, J. "Force-derivative feedback semi-active control of base-isolated buildings using large-scale MR fluid dampers", Struct. Control Heal. Monit., 19(1), pp. 120-145 (2012).

26. Tsouroukdissian, A.R., Ikhouane, F. and Rodellar, J. "Modeling and identification of a small-scale magnetorheological damper", J. Intell. Mater. Syst. Struct., 20(7), pp. 825-835 (2009).

27. Dai, Z.B., Huang, J.Z. and Wang, H.X. "Semi-active control of a cable-stayed bridge under multiple-support excitations.", J. Zhejiang Univ. Sci., 5(3), pp. 317-25 (2004).
28. Pourzeynali, S., Reliability Analysis of Suspension Bridges for Wind Forces, IIT- Delhi (2001).

29. Chopra, A.K., Dynamics of Structures: Theory and Applications to Earthquake Engineering, Indiana, U.S.A.: Prentice Hall (1995).

30. Abdel-Ghaffar, A.M. "Vertical vibration analysis of suspension bridges", J. Struct. Div., 106(10), pp. 2053-2075 (1980).

31. Ogata, K., Modern Control Engineering, 3rd Ed., USA: Prentice-Hall, Inc. (1998).

32. Pourzeynali, S., Semi-Active Control of Suspension Bridges Using MR Dampers and Fuzzy Logic, University of Guilan (2013).

33. Spencer Jr, B.F. "Recent trends in vibration control in the U.S.A.", in the 3rd International Conference on Motion and Vibration Control in Chiba, pp. K1-K6 (1996).

34. Gamota, D.R. "Dynamic mechanical studies of electrorheological materials: Moderate frequencies", $J$. Rheol. (N. Y. N. Y)., 35(3), pp. 399-425 (1991).

\section{Biographies}

Saeid Pourzeynali received his MS degree in Structural Engineering, in 1989, from Tehran University, Iran, and joined the University of Guilan, Rasht, Iran, as Lecturer in the Department of Civil Engineering. In 1991, Dr. Pourzeynali obtained his $\mathrm{PhD}$ degree in Structural Engineering from IIT Delhi, India, and is currently at the University of Guilan, Iran. His research interests span a wide range of specialized fields, including structural dynamics, earthquake engineering, random vibrations, reliability analysis, structural control and optimization, and dynamics of cable supported bridges. Dr. Pourzeynali has more than 24 years experience in teaching and has supervised more than $30 \mathrm{MS}$ degree students. He has published more than 90 international journal and conference papers, and has received various awards, including "best research study on cable supported bridges" in 2004 from the Vice-Chancellor for Research at the University of Guilan.

Arash Bahar was born in 1967 in Rasht, Iran. After graduation from the Civil Engineering Department at the Isfahan University, Isfahan, Iran, in 1987, he continued his studies toward MSc in Structural Engineering at the School of Engineering, Shiraz University, Shiraz, Iran. He then joined Guilan University in 1993. He received his $\mathrm{PhD}$ degree in Earthquake Engineering from the "Universitat Politécnica de Cataluña", in 2009 in Barcelona, Spain. He is presently Assistant Professor of Structural Engineering division of the Faculty of Engineering in the University of Guilan. His research interests include: structural control, identification, 
linear/non-linear dynamic analysis, MR damper/semiactive devices, earthquake engineering, and steel structural design.

Solmaz Pourzeynali was born in 1988 in Tehran, Iran. She obtained her BSc degree in Civil Engineering from University of Guilan, Iran, in 2010, and her MSc degree in Structural Civil Engineering at the same university in 2013. Her research interests include structural dynamics, earthquake engineering and bridge engineering. She, also, has several publications in suspension bridges. 